Data Article

\title{
Effect of water-soluble chitosan on the electrochemical corrosion behaviour of mild steel
}

\author{
O.S.I. Fayomi ${ }^{\text {add,* }}$, I.G. Akande ${ }^{\mathrm{b}}$, O.O. Oluwole ${ }^{\mathrm{b}}$, D. Daramola ${ }^{\mathrm{c}}$ \\ a Department of Mechanical Engineering, Covenant University, Ota, Ogun State, Nigeria \\ ${ }^{\mathrm{b}}$ Department of Mechanical Engineering, University of Ibadan, Ibadan, Oyo State, Nigeria \\ ${ }^{c}$ Department of Biomedical Engineering, Bells University of Technology, Ota, Ogun State, Nigeria \\ ${ }^{\mathrm{d}}$ Department of Chemical, Metallurgical and Materials Engineering, Tshwane University of Technology, Pretoria, South Africa
}

\section{A R T I C L E I N F O}

\section{Article history:}

Received 24 July 2018

Revised 18 October 2018

Accepted 19 October 2018

Available online 22 October 2018

\begin{abstract}
A B S T R A C T
This article outlines the role of chitosan as a potent inhibitor on mild steel in $3.65 \% \mathrm{NaCl}$. The protective ability of chitosan was evaluated by potentiodynamic polarization (PP) measurements in $36.5 \%$ sodium chloride medium. The outcome of the experiment shows that mild steel in sodium chloride solution containing chitosan nanoparticles exhibit better corrosion protection than mild steel in $\mathrm{NaCl}$ solution alone because the anodic and cathodic site of the steel were blocked by chitosan nanoparticles, thereby minimising the incursion of the salt solution by forming a thin film on the mild steel surface. The inhibitive efficiency of chitosan nanoparticles was also studied using weight loss. The weight loss by mild steel in $\mathrm{NaCl}$ solution was found to be higher than those immersed in $\mathrm{NaCl}$-chitosan nanoparticulate solutions. The loss in weight reduces as the concentration of chitosan nanoparticles increases, indicating the fortifying ability of chitosan nanoparticles. Results obtained show that chitosan could offer inhibition efficiency above $90 \%$. The mixed inhibition characteristic of chitosan was demonstrated by the Tafel curve. The Langmuir isotherm possesses an $R^{2}$ value of 0.9957 indicating the effectiveness of chitosan as an inhibitor.
\end{abstract}

(C) 2018 Published by Elsevier B.V.

\section{Specifications table}

$\begin{array}{ll}\text { Subject area: } & \text { Mechanical engineering science, Material science and engineering, Chemical engineering } \\ \text { Compound: } & \text { Chitosan, NaCl } \\ \text { Data category: } & \text { Corrosion rate by potentiodynamic polarization }(\mathrm{PP}) \text { instrument (NOVA 2.1.2) } \\ \text { Data acquisition: } & \text { Potentiodynamic polarization measurement and weight loss } \\ \text { Data type: } & \text { Raw, analysed } \\ \text { Procedure: } & \text { Mild steels were immersed in } 3.65 \% \mathrm{NaCl} \text { containing chitosan nanoparticles of different concentration. The corrosion } \\ & \text { rates were examine and analysed using potentiodynamic polarization measurement and weight loss. }\end{array}$

\section{Rationale}

Corrosion of metals and alloys is an underlying process playing vital functions in safety and economic advancement. Mild steel has been found to have versatile applicability in a production of engines and tools despite its ability to corrode [1-3]. Due to this setback, a lot of defensive techniques have been adopted to enhance the service life of mild steel, not only

\footnotetext{
* Corresponding author.

E-mail address: ojo.fayomi@covenantuniversity.edu.ng (O.S.I. Fayomi).
} 
Table 1

Chemical composition of mild steel used (wt.\%).

\begin{tabular}{lllllllll}
\hline Element & $\mathrm{Mn}$ & $\mathrm{C}$ & $\mathrm{S}$ & $\mathrm{Si}$ & $\mathrm{P}$ & $\mathrm{Ni}$ & $\mathrm{Al}$ & $\mathrm{Fe}$ \\
\hline Composition & 0.45 & 0.15 & 0.031 & 0.18 & 0.01 & 0.008 & 0.005 & 99.346 \\
\hline
\end{tabular}

Table 2

Electrochemical parameters from Tafel curve.

\begin{tabular}{llllllll}
\hline Samples & $E_{\text {corr }}(\mathrm{V})$ & $I_{\text {corr }}\left(\mathrm{A} / \mathrm{cm}^{2}\right)$ & $\mathrm{CR}(\mathrm{mm} /$ year $)$ & $b_{\mathrm{a}}(\mathrm{V} / \mathrm{dec})$ & $b_{\mathrm{c}}(\mathrm{V} / \mathrm{dec})$ & $\mathrm{PR}(\Omega)$ & $\mathrm{IE}(\%)$ \\
\hline Control & -1.1655 & 0.00074955 & 8.7097 & 0.088705 & 0.045097 & 17.323 & 0 \\
$\mathrm{MS}_{1}-0.3 \mathrm{CH}$ & -1.1841 & 0.0003073 & 3.5708 & 0.027093 & 0.02074 & 17.902 & 59 \\
$\mathrm{MS}_{2}-0.6 \mathrm{CH}$ & -1.1875 & 0.00020887 & 2.4271 & 0.019162 & 0.011755 & 18.148 & 72.13 \\
$\mathrm{MS}_{3}-0.9 \mathrm{CH}$ & -1.1945 & 0.00011895 & 1.3822 & 0.011944 & 0.00955335 & 19.357 & 84.13 \\
$\mathrm{MS}_{4}-1.2 \mathrm{CH}$ & -1.1951 & 0.00007356 & 0.8548 & 0.0082416 & 0.0080543 & 24.049 & 90.19 \\
\hline
\end{tabular}

against corrosion but also against operational wear [4-6]. The study of the corrosion repression of mild steel has, therefore, gained momentum across multidisciplinary fields [7]. Because of the attack of mild steel in aggressive acidic and saline environments, inhibitors are commonly used to suppress the damaging effect of corrosion. The impact of corrosion on steel is chiefly a surface event $[8,9]$. However, the medium is one of the main factors that influence corrosion, having a large tendency to alter material properties and behavioural performance in operation [10-12].

A lot of methods have been used to combat the attack of corrosion on mild steel but the use of inhibitive particulates have been found effective and applicable [11-13]. Most inhibitors have been found to be relatively cheap, environmentfriendly and also pave way for easy reproducibility $[14,15]$. A good example is the chitosan found to be richly available in the [16]. Its broad range of application can be attributed to its unique properties, which include non-toxicity, bio-compatibility, bio-degradability and great film forming capability on steel [15-17]. Chitosan's anti-corrosion capability is also a function of its molecular structure. Chitosan is naturally equipped with amino and hydroxyl that have the propensity to form bonding on the surface of steel metal $[18,19]$ resulting in corrosion protection. The bond formed on the increase the surface energy of the steel and further aiding molecular adhesion after a long period of immersion thereby resulting in corrosion inhibition [20-22].

\section{Procedure}

The corrosion experiment was executed in a standard three-electrode cell using potentiostat (PGSTAT 101) in connection with NOVA 2.1.2 software. The working electrode is a mild steel specimen of dimension $(20 \times 20 \times 2)$ mm whose composition is stated in Table 1 . Saturated $\mathrm{Ag} / \mathrm{AgCl}$ electrode and platinum electrode were used as reference and counter electrode, respectively. Different grades of emery papers were used to clean the working electrodes and rinsed quickly with distilled water. A copper wire was fused to the sample, which was afterwards implanted in epoxy resin. This was allowed to immerse in the electrolyte solution $(3.65 \% \mathrm{NaCl})$ for about $10 \mathrm{~min}$ to attain the steady state potential. The polarization plots were obtained from the cathodic potential of $-1.5 \mathrm{~V}$ to anodic potential of $1.5 \mathrm{~V}$ at a scan rate of $0.005 \mathrm{~m} / \mathrm{s}$.

The same procedure was carried out with four other mild steel samples varying the concentration of chitosan nanoparticles in four different $3.65 \% \mathrm{NaCl}$ solution and the effects were noted. To check for reproducibility each experiment was repeated four times. Values of the electrochemical parameter obtained from the extrapolation of the polarization curves are indicated in Table 2. The polarization curves are an indication that both the cathodic and anodic metal dissolution reactions have been influenced by the addition of chitosan nanoparticles. After the corrosion experiment, weight loss measurement of each of the samples was carried out so as to note the influence of chitosan on the dissolution of mild steel in the saline medium.

\section{Data, values and validation}

The corrosion experiment data are represented graphically in Figs. 1 and 2 These figures are the plot of data after varying the concentrations of water-soluble chitosan in the saline medium. Each of the plots shows indispensable details. The values in Table 2 indicate the parameters from the polarization curve in Fig. 2.

The values of the data presented graphically and in tables include:

- The OCP in Fig. 1. There was a shift in potential towards more positive values with respect to the control as the concentration increases. This could be attributed to the adsorption of chitosan molecules on the anodic site of the mild steel. It is important to note that the OCP vs. time curve for the inhibited and uninhibited samples were near straight line indicating that steady state potential was attained [23].

- Tafel plot in Fig. 2 suggesting that polarization has taken place because of the presence of both cathodic and anodic branch [24]. 


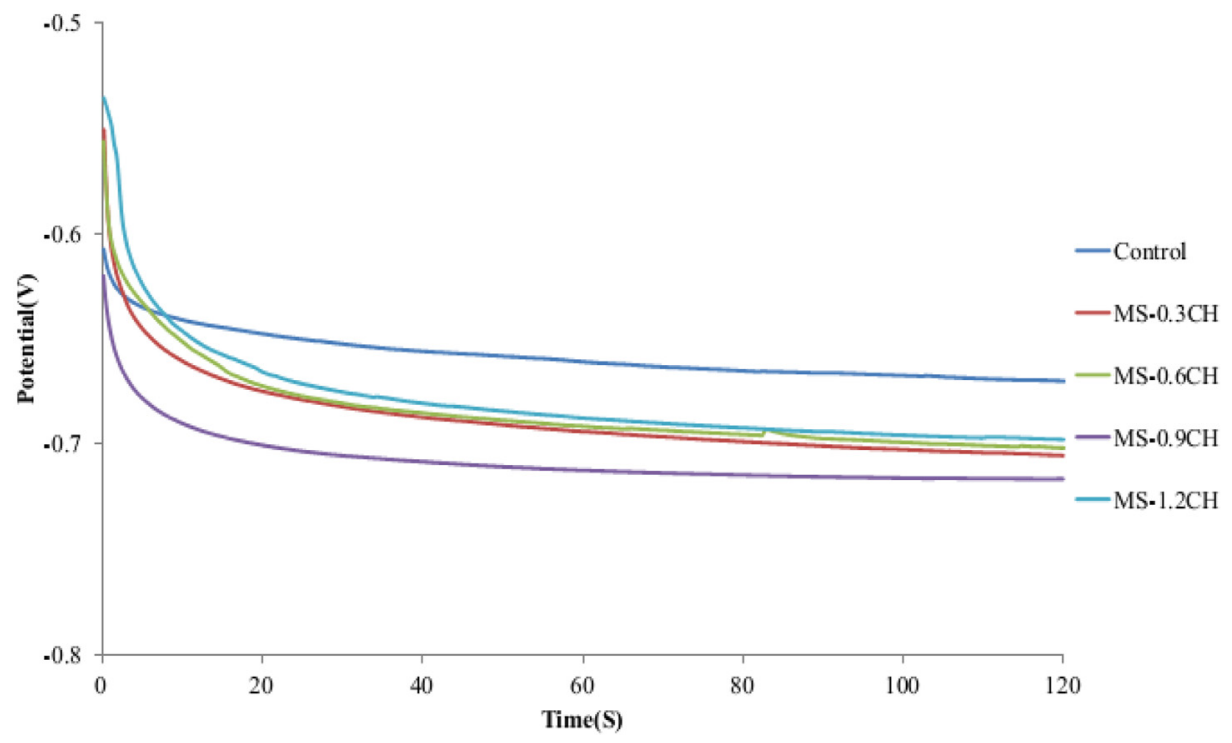

Fig. 1. Graphical plot of open circuit potential of mild steel with and without inhibitor versus time.

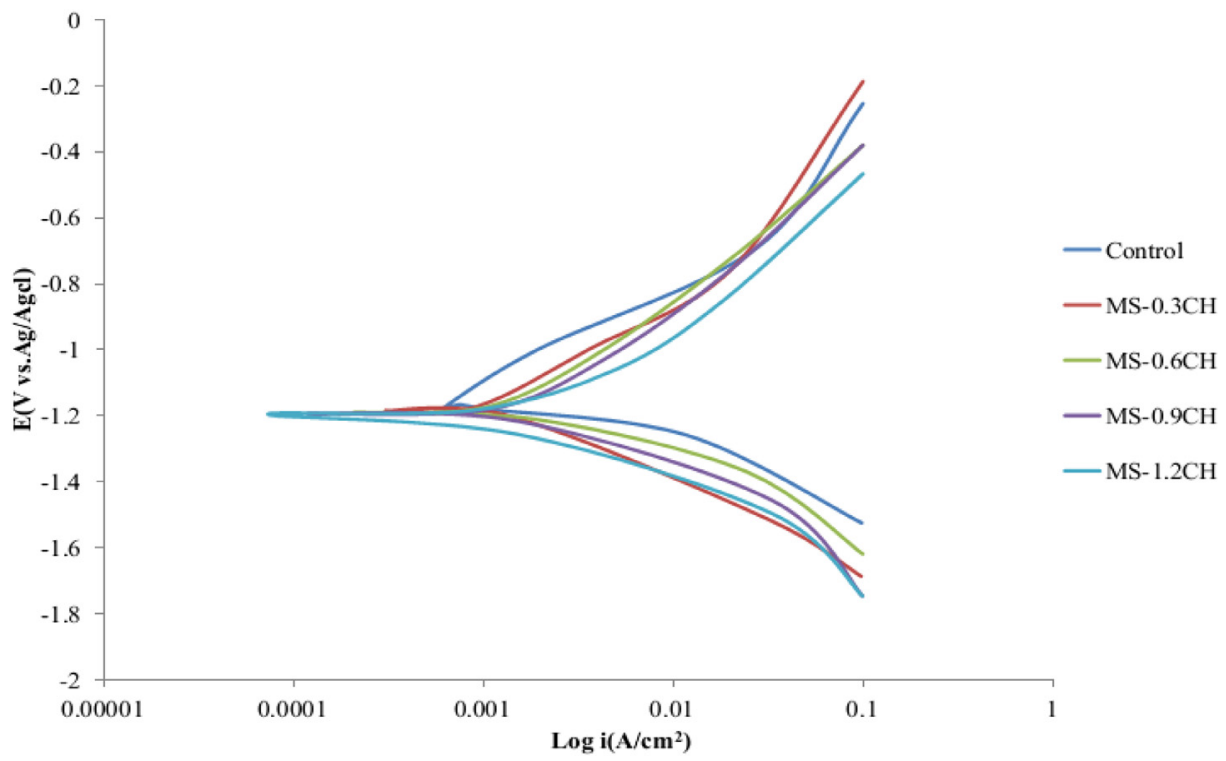

Fig. 2. Potentiodynamic polarization curve of uninhibited and inhibited samples.

- Evaluation of $b_{\mathrm{c}}$ and $b_{\mathrm{a}}$ (cathodic and anodic slope), as well as $I_{\text {corr }}$; the values of the corrosion current densities and corrosion potential $\left(E_{\text {corr }}\right)$ were obtained by Tafel extrapolation of the current and potential lines. It is worthy of note that addition of chitosan hindered the exchange of current density, this was confirmed by movement of the anodic and cathodic curves to the direction of lower current density [25,26]. Table 2 indicates that an increase in chitosan nanoparticles from $0.3 \mathrm{~g}$ through $0.6 \mathrm{~g}, 0.9 \mathrm{~g}$ and finally $1.2 \mathrm{~g}$ significantly minimise the corrosion rate of mild steel. However, $E_{\text {corr }}$ for the varying concentrations is closed, suggesting that polarization is a mixed type which shows that the water-soluble chitosan is a mixed-type inhibitor [27-29].

It is also worthy of note in Table 2 that the corrosion rate per year was on the decline as the concentration of the chitosan nano inhibitor increases. It was highest for the control and lowest for $\mathrm{MS}_{4}-1.2 \mathrm{CH}$ which shows that corrosion rate reduces with increase in chitosan [30]. The surface coverage $(\theta)$ by molecules of the inhibitor was obtained using Eq. 1 [31]

$$
\theta=\left(I_{0, \text { corr }}-I_{\text {corr }}\right) / I_{0, \text { corr }}
$$

The value of $(\theta)$ was maximum when chitosan concentration reaches the maximum values of $1.2 \mathrm{~g}[32,33]$.

Inhibitorefficiency, $\mathrm{IE}=\left(1-I_{\text {corr }} / I_{0, \text { corr }}\right) \times 100$ 


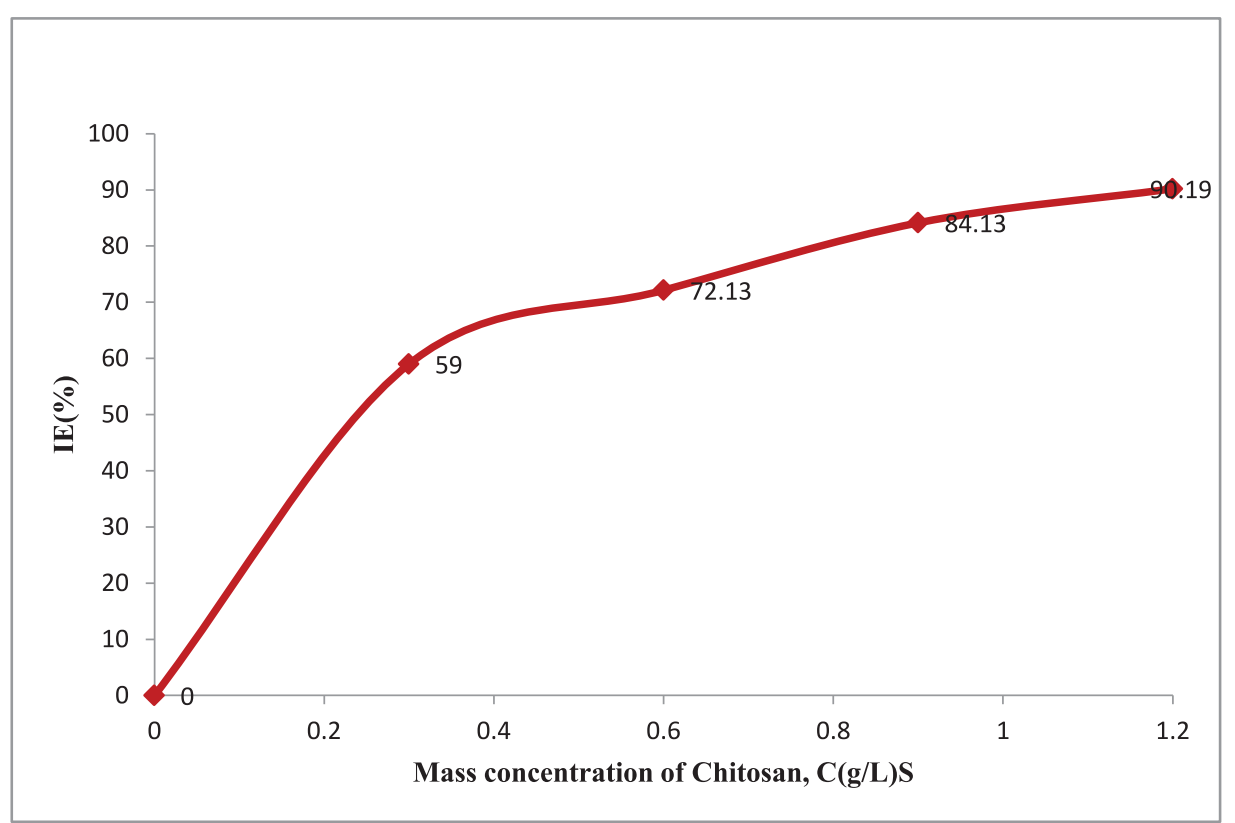

Fig. 3. Inhibition efficiency of chitosan inhibitors in $36.5 \% \mathrm{NaCl}$.

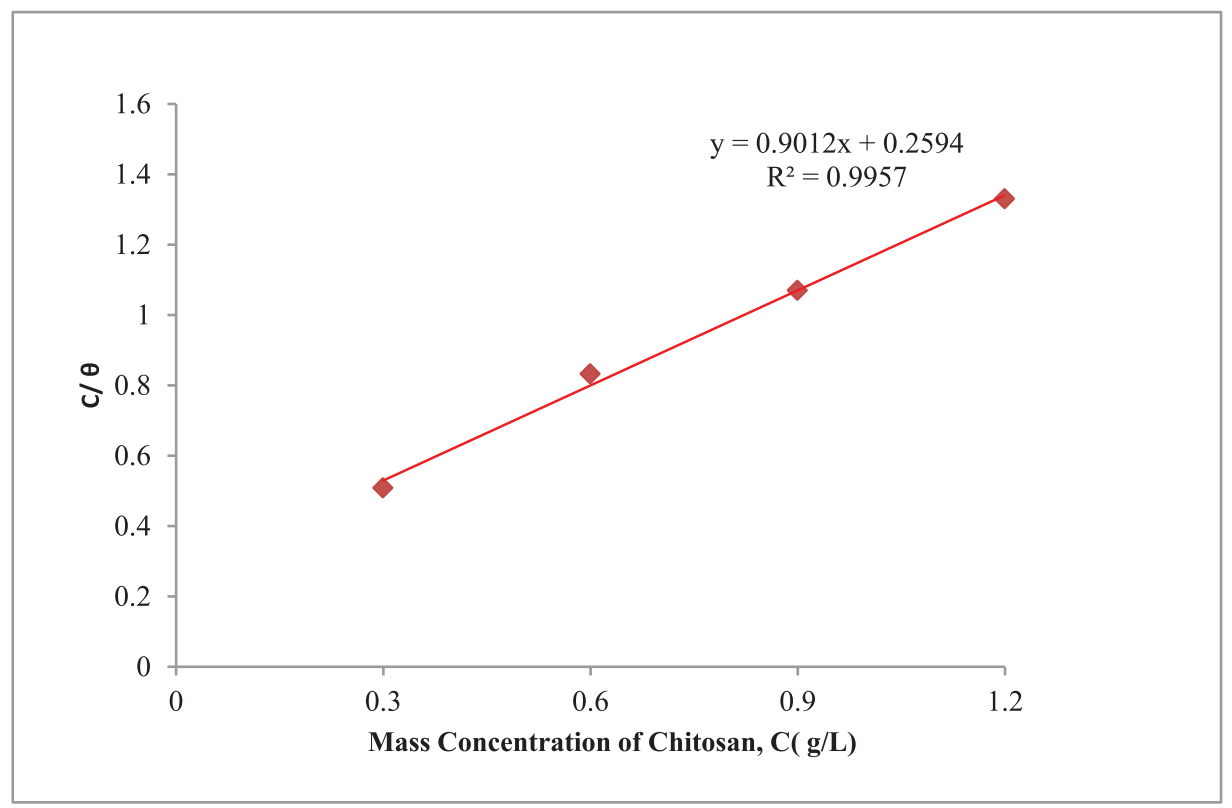

Fig. 4. Langmuir adsorption isotherms for the inhibited samples.

From the variation of the corrosion inhibition efficiency of chitosan inhibitors with their concentration in $36.5 \% \mathrm{NaCl}$ shown in Fig. 3, a conclusion could be reached that the water-soluble chitosan is highly efficient. There was an improvement in the inhibition effectiveness as the concentration of chitosan increases. The improvement results from the chitosan adsorption on the steel surface. The resistance to polarization was also found to have increased with an increase in the mass concentration of chitosan as shown in Table 2, ascertaining the corrosion retardation potential of chitosan. Fig. 4 shows the Langmuir isotherm with an $R^{2}$ value of 0.9957. The closeness of $R^{2}$ to unity confirms the validity of the experiment [34-36].

After the electrochemical experiment, loss in masses was observed, it was highest for the uninhibited mild steel used as the control and lowest for $\mathrm{MS}_{4}$ (Mild steel immersed in $\mathrm{NaCl}$ containing $1.2 \mathrm{~g}$ of chitosan) as showed in Table 3. This is an indication that chitosan offers an excellent resistance to corrosion and wear resistance to mild steel. 
Table 3

Mass of steel loss after immersion, surface coverage and $C / \theta$.

\begin{tabular}{llll}
\hline Samples after immersion & Loss $(\mathrm{g})$ & Surface coverage $(\theta)$ & $C / \theta$ \\
\hline Control & 0.0186 & 0 & 0 \\
SS $_{1}$ & 0.0152 & 0.5900 & 0.5085 \\
$\mathrm{MS}_{2}$ & 0.0123 & 0.7210 & 0.8322 \\
$\mathrm{MS}_{3}$ & 0.0121 & 0.8410 & 1.0702 \\
$\mathrm{MS}_{4}$ & 0.0110 & 0.9020 & 1.3304 \\
\hline
\end{tabular}

\section{Acknowledgement}

The author acknowledges the financial support offered by Covenant University to undertake this research

\section{Supplementary materials}

Supplementary material associated with this article can be found, in the online version, at doi:10.1016/j.cdc.2018.10.006.

\section{References}

[1] M. Abdulwahab, O.S.I. Fayomi, Corrosion inhibition of mild steel in Sesamum indicum-2 $\mathrm{M} \mathrm{HCl} / \mathrm{H}_{2} \mathrm{SO}_{4}$ interface, Int. J. Electrochem. Sci. 7 (2012) 5805-5816.

[2] N. Malatji, O.S.I. Fayomi, The effect of nanoparticulate loading on the fabrication and characterization of multi-doped $\mathrm{Zn}_{-} \mathrm{Al}_{2} \mathrm{O}_{3}-\mathrm{Cr}_{2} \mathrm{O}_{3}$ hybrid coatings on mild steel, Int. J. Adv. Manuf. Technol. 90 (2017) 2443-2452.

[3] O.A. Omotosho, O.O. Ajayi, O.S Fayomi, V.O. Ifepe, Assessing the deterioration behaviour of mild steel in 2 M sulphuric acid using Bambusa glauscescens, Int. J. Appl. Eng. Res. Dindigul 2 (2011) 406-418.

[4] O.S.I. Fayomi, An investigation of the properties of Zn coated mild steel, Int. J. Electrochem. Sci. 7 (2012) 6555-6570.

[5] M.H.O. Ahmed, A.A. Al-Amiery, Y.K. Al-Majedy, A.A.H. Kadhum, A.B. Mohamad, T.S. Gaaz, Synthesis and characterization of a novel organic corrosion inhibitor for mild steel in $1 \mathrm{M}$ hydrochloric acid, Results Phys. 8 (2018) 728-733.

[6] R. Jia, J.L. Tan, P. Jin, D.J. Blackwood, Xu D., T. Gu, Effects of biogenic $\mathrm{H}_{2} \mathrm{~S}$ on the microbiologically influenced corrosion of C1018 carbon steel by sulfate reducing Desulfovibrio vulgaris biofilm, Corros. Sci. 130 (2018) 1-11.

[7] S.A. Umoren, U.M. Eduok, Application of carbohydrate polymers as corrosion inhibitors for metal substrates in different media: a review, Carbohydr Polym. 140 (2016) 314-341.

[8] O.S.I. Fayomi, V.S Aigbodion, Properties of Tic/Tib modified Zn-Tic/Tib ceramic composite coating on mild steel, J. Fail. Anal. Prev. 15 (2015) 54-64.

[9] R. Gan, D. Wang, Z.H. Xie, L. He, Improving surface characteristic and corrosion inhibition of coating on Mg alloy by trace stannous (II) chloride, Corros. Sci. 123 (2017) 147-157.

[10] G.N. Devi, J. Saranya, N. Manjubaashini, T.D. Thangadurai, S.M. Roopan, S. Chitra, Polyamidoaminoepichlorohydrin resin a novel synthetic anti-corrosive water soluble polymer for mild steel, Prog. Org. Coat. 109 (2017) 117-125.

[11] A. Jmiai, B.El Ibrahimi, A. Tara, R. Oukhrib, S.El Issami, O. Jbara, M. Hilali, Chitosan as an eco-friendly inhibitor for copper corrosion in acidic medium: protocol and characterization, Cellulose 24 (2017) 3843-3867.

[12] M. Abdulwahab, A. Kasim, O.S. Fayomi, F. Asuke, Inhibitive effect of Arachis hypogeae on the corrosion of mild steel in sulphuric acid solution, J. Mater. Environ. Sci. 3 (2012) 1177-1182.

[13] K.K. Anupama, K. Ramya, A. Joseph, Electrochemical measurements and theoretical calculations on the inhibitive interaction of Plectranthus amboinicus leaf extract with mild steel in hydrochloric acid, Measurement 95 (2017) 297-305.

[14] O.S. Fayomi, M. Abdulwahab, Degradation behaviour of aluminium in $2 \mathrm{M} \mathrm{HCl} / \mathrm{HNO}_{3}$ in the presence of arachis hypogeae natural oil, Int. J. Electrochem. Sci. 7 (2012) 5817-5827.

[15] L.S. Barreto, M.S. Tokumoto, I.C. Guedes, H.G.D. Melo, Amado F., V.R Capelossi, Study and assessment of the efficiency of the cocoa bark extracted from the Theobroma cacao as an inhibitor of the corrosion of carbon steel in substitution of benzotriazole, Mater. Res. 21 (2017) 1-9.

[16] D.B. Kayan, M. İlhan, D. Koçak, Chitosan-based hybrid nanocomposite on aluminium for hydrogen production from water, Ionics 24 (2018) 563-569.

[17] G.A. El-Nagar, I. Derr, A. Fetyan, C. Roth, One-pot synthesis of a high performance chitosan-nickel oxyhydroxide nanocomposite for glucose fuel cell and electro-sensing applications, Appl. Catal. B: Environ. 204 (2017) 185-199.

[18] R. Menaka, S. Subhashini, Chitosan Schiff base as effective corrosion inhibitor for mild steel in acid medium, Polym. Int. 66 (2017) 349-358.

[19] I. Younes, M. Rinaudo, Chitin and chitosan preparation from marine sources. Structure, properties and applications, Mar. Drugs 13 (2015) $1133-1174$.

[20] M.A. Amin, K.F. Khaled, S.A. Fadl-Allah, Testing validity of the Tafel extrapolation method for monitoring corrosion of cold rolled steel in HCl solutions-experimental and theoretical studies, Corros. Sci. 52 (2016) 140-151.

[21] Y. Sangeetha, S. Meenakshi, C.S. Sundaram, Interactions at the mild steel acid solution interface in the presence of O-fumaryl-chitosan: electrochemical and surface studies, Carbohydr. Polym. 136 (2016) 38-45.

[22] V. Zargar, M. Asghari, A. Dashti, A review on chitin and chitosan polymers: structure, chemistry, solubility, derivatives, and applications, ChemBioEng Rev. 2 (2015) 204-226

[23] O.S.I. Fayomi, I.G. Akande, A.P.I. Popoola, Corrosion protection effect of chitosan on the performance characteristics of A6063 alloy, J. Bio-Tribo-Corros. 4 (2018) 73. https://doi.org/10.1007/s40735-018-0192-6.

[24] O.S.I Fayomi, A.A. Atayero, P. Mubiaye, I.G. Akande, P.A. Adewuyi, M.A. Fajobi, W.A. Ayara, Mechanical and opto-electrical response of embedded smart composite coating produced via electrodeposition technique for embedded system in defence application, J. Alloys Compd. 773 (2019) $305-313$.

[25] A. Dutta, S.K. Saha, U. Adhikari, P. Banerjee, D. Sukul, Effect of substitution on corrosion inhibition properties of 2-(substituted phenyl) benzimidazole derivatives on mild steel in $1 \mathrm{M} \mathrm{HCl}$ solution: a combined experimental and theoretical approach, Corros. Sci. 123 (2017) $256-266$.

[26] L. Rossrucker, A. Samaniego, J.P. Grote, A.M. Mingers, C.A. Laska, N. Birbilis, K.J.J. Mayrhofer, The pH dependence of magnesium dissolution and hydrogen evolution during anodic polarization, J. Electrochem. Soc. 162 (2015) 333-339.

[27] H. Lgaz, K.S. Bhat, R. Salghi, S. Jodeh, M. Algarra, B. Hammouti, A. Essamri, Insights into corrosion inhibition behavior of three chalcone derivatives for mild steel in hydrochloric acid solution, J. Mol. Liquids 238 (2017) 71-83.

[28] S. Perumal, S. Muthumanickam, A. Elangovan, R. Karthik, K.K. Mothilal, Bauhinia tomentosa leaves extract as green corrosion inhibitor for mild steel in $1 \mathrm{M} \mathrm{HCl}$ medium, J. Bio-Tribo-Corros. 3 (2017) 13.

[29] B.A. Abd-El-Nabey, Y.M. Goher, H.A. Fetouh, M.S. Karam, Anticorrosive properties of chitosan for the acid corrosion of aluminium, Portug. Electrochim. Acta 33 (2015) 231-239.

[30] Y. Liu, C. Zou, X. Yan, R. Xiao, T. Wang, M. Li, $\beta$-Cyclodextrin modified natural chitosan as a green inhibitor for carbon steel in acid solutions, Ind. Eng. Chem. Res. 54 (2015) 5664-5672. 
[31] K. Zakaria, N.A. Negm, E.A. Khamis, E.A. Badr, Electrochemical and quantum chemical studies on carbon steel corrosion protection in 1 M $\mathrm{H}_{2} \mathrm{SO}_{4}$, using new eco-friendly Schiff base metal complexes, J. Taiwan Inst. Chem. Eng. 61 (2016) 316-326.

[32] S.F. Yang, Y. Wen, P. Yi, K. Xiao, C.F. Dong, Effects of chitosan inhibitor on the electrochemical corrosion behaviour of 2205 duplex stainless steel, Int. J. Miner. Metall. Mater. 24 (2017) 1260-1266.

[33] M. Moses, A. Saviour, Performance evaluation of a chitosan/silver nanoparticles composite on ST37 steel corrosion in a $15 \%$ HCl solution, ACS Sustain. Chem. (2017) 1-44.

[34] S. John, A. Joseph, T. Sajini, A.J. Jose, Corrosion inhibition properties of 1,2,4-hetrocyclic systems: electrochemical, theoretical and Monte Carlo simulation studies, Egypt. J. Petroleum 26 (2017) 721-732.

[35] S. John, R. Jeevana, K.K. Aravindakshan, A. Joseph, Corrosion inhibition of mild steel by N(4)-substituted thiosemicarbazone in hydrochloric acid media, Egypt. J. Petroleum 26 (2017) 405-412.

[36] O.S.I. Fayomi, A.P.I. Popoola, T. Oloruntoba, A.A. Ayoola, Inhibitive characteristics of cetylpyridinium chloride and potassium chromate addition on type A513 mild steel in acid/chloride media, Cogent Eng. 4 (2017) 1318736. 